\title{
Journal of Applied Pharmaceutical Science
}

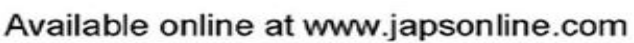

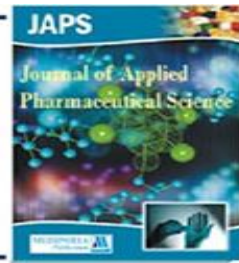

ISSN: 2231-3354

Received on: 22-05-2012

Revised on: 30-05-2012

Accepted on: 07-06-2012

DOI: 10.7324/J APS.2012.2701

Mohanad Rahman Alwan,

Sami Abob Radman Al-Dubai, Redhen Ahmed Mohammed AlNaggar, Mohammed Faez Baobeid, Mustafa Fadil Mohammed and Mahfouch Abchulghani International medical schoo, Management and ScienceU ni versity 40100 Shah Alam, Malaysi a.
For Correspondence Mohanad Rahman Alwan International medical schod, Management and Science U ni versity 40100 Shah Alam, Malaysia.

\section{The Effect of Quramin and Tocotriend on the Development of EyeDisease}

\author{
Mohanad Rahmen Alwen, Sami Abcb Radmen Al-Dubai, Rechwen Ahmed \\ Mohammed Al-Naggar, Mohammed Faez Badbaid Mustafa Fadl \\ Mohammed and Mahfouch Abodughani
}

\begin{abstract}
There is growing evidence that inflammation may be one of the causative factors of many chronic diseases especially which is related to eyes such as cataract,age-related macular degeneration and uveitis. Several cytokines such as IL-1,IL-6, RANKL, OPG, and M-CSF were implicated in the pathogenesis of chronic diseases. Anticytokine therapy using cytokine antagonists such as IL-receptor antagonist and TNF-binding protein was able to suppress the activity of the respective cytokines and prevent bone loss. Few animal studies have shown that vitamin $\mathrm{E}$ in the forms of palm-derived tocotrienol and $\alpha$-tocopherol may prevent chronic eye disease in rat models by suppressing IL-1 and IL-6. Free radicals are known to activate transcription factor $\mathrm{NF} \kappa \mathrm{B}$ which leads to the production of bone resorbing cytokines. Tocotrienol, a potent antioxidant, may be able to neutralize free radicals before they could activate $\mathrm{NF} \kappa \mathrm{B}$, therefore suppressing cytokine production and inflammatory reaction. Curcumin is widely reported to have potent anti-oxidative, anti-inflammatory and anticarcinogenic effects. The anti-inflammatory action of curcumin seems to be closely related to inhibition of TNF- $\alpha$ and other inflammatory cytokines production and suppression of NF- $\kappa \mathrm{B}$ activation by blocking phosphorylation of inhibitory factor I-kappa B kinase (IкB) Tocotrienol and curcuminhave also been shown to inhibit COX-2, the enzyme involved in inflammatory reactions of the these studied, tocotrienol seemed to be better than tocopherols in terms of its ability to suppress inflammation induced by cytokines.
\end{abstract}

Keywords: Curcumin, Tocotrienol, Eye Disease, Inflammation.

\section{INTRODUCTION}

The free radical (ROS) defined as any atom or molecule possessing unpaired electrons. Molecular oxygen $\mathrm{O}^{-}$is a biradical with two such unpaired electrons. The biologically relevant free radicals derived from oxygen are the superoxide anion $\left(\mathrm{O}_{2}^{-}\right)$, the perhydroxyl radical (protonated superoxide, $\mathrm{HO}^{-}$), the hydroxyl radical $\left(\mathrm{HO}^{-}\right)$, and free radical nitric oxide $\left(\mathrm{NO}^{-}\right)$.

As antioxidant is a molecule capable of slowing or preventing theoxidation of other molecules. Antioxidants action can terminate these chain reactions byremoving free radicals intermediates (Sies et al., 1997). The use of antioxidants inpharmacology is intensively studied, particularly as treatments forstroke and neurodegenerative diseases. However, it is unknownwhether oxidative stress is the cause or the consequence of disease (Bjelakovic et al., 2007). 


\section{Oxidative stress and free radicles}

The eye is a highly metabolically active structure, continually bathed in light and the absorption and metabolism will be highly functioning. Thus, oxidative and particularly photooxidative processes are critical factors in ocular pathologic conditions but are often poorly recognized by investigating ocular disease regarding to (Jean et al., 1999; Jennifer et al., 2008). Oxidative stress is a key player in the mechanism of inflammation; thus, we should not be surprised that it is important in eye disease conjunctiva, cornea and uvea (Saraswathy and Rao, 2009). As well as in cataract formation in the lens, retinal degeneration and in optic nerve pathologic conditions, inflammatory in optic neuritis and degenerative in glaucoma due to oxidative stress which occurs throughout the eye and is involved in many different types of tissue damage (Wu et al., 2005; Ferreira et al., 2004; Biswas et al., 2005). This effect of oxidative stress has been increasingly recognized as important factor in pathologic conditions generally in ocular pathologic conditions specifically in the past decade (Mittag, 1984; Bacsi et al., 2005; Kruzel et al., 2006).

In Ophthalmology, the relation between oxidative stress and aging has been given attention for some diseases to aging like age-related macular degeneration, cataract and dystrophy. Regarding to Imamura et al., (2006) the amount and activity of SOD were the highest among the in the human retina, it seemed reasonable to hypothesize that the lack of SOD would accelerate age-related pathological changes in the human retina (Liang \& Godley, 2003; Taysi et al., 2007). In many experimental research of uveitis generally involve the posterior segment and retinal mitochondria that exhibit signs of oxidative stress, which seems to result from the up regulation of inducible nitric oxide synthase (iNOS) in photoreceptor mitochondria and retinal cytokine generation by antigen-specific infiltrating $\mathrm{T}$ cells (Rajendrum et al., 2007; David et al., 2008).

The relevance to the anterior uveitis seen more commonly, oxidative stress is also seen in models of anterior uveitis, such as that induced by endotoxin (Bhattacherjee et al., 1983; Yan Guex et la., 1996; Satici et al., 2004; Yadav., et al., 2009). The level of malondialdehyde (MDA) in aqueous humor which is consider important key marker of oxidative stress (Rahman and Biswas, 2004). The trophic factor pigment epithelialderived factor (PEDF) is produced by the retinal pigment epithelium and also by the epithelium of the ciliary body, from whence it is secreted into the aqueous humor (Ortego et al., 1996; Neiderkorn et al., 2007).

Imamura et al., (2006) have been investigated the agerelated changes of the retinas of mice and found that these mice have many of the key elements of human age-related macular degeneration including thickened Bruch's membrane, and retina neovascularization. Moreover, the retinal pigment epithelium (RPE) cells of these mice showed signs of oxidative stress damage, and their junction integrities have been damaged (Bilgihan et al., 2003).In the other hand some studies revealed that the mechanism of causative role of oxidative stress in the pathogenesis of retinal degeneration and demonstrated a critical role of SOD in protecting the RPE from age-related degeneration (Imamura et al., 2006; Wakamatsu et al., 2008). In vivo studies, it provides a steady supply of free radicals since it is a chain reaction leading to the formation of organic peroxides. The accumulation of peroxides can lead to damage effect on cellular vitality, which might be developing to degeneration and necrosis (Chung et al., 1999; Tezel et al., 2001; Tezel, 2006).

The eye is unique in possessing abundant quantities of antioxidant enzymes and other antioxidant agents. The antioxidant enzymes which include superoxide dismutase (SD), catalase (CAT), glutathione peroxidase (GPX), and glutathione transferase (Delcourt. et al., 2003; Gritzet al., 2006; Jennifer et al., 2008), all ofthese enzymes are distributed in the corneal epithelium and endothelium, lens epithelium, retina and retinal pigment epithelium. The eye also contains other antioxidants, such as ascorbate, vitamin E, ceruloplasmin, and transferrin (Behndig et al., 2001). These agents and the enzymes are contributed to prevent the damaging effects of oxygen and its metabolites (Koh et al., 2000; Balci et al., 2007). As the balance between the production and catabolism of oxidants by cells and tissue is critical for maintenance of the biologic and structural integrity of the tissue, the role of free radical generation in initiation of retinal or other intraocular tissue damage should be studied in clinically relevant models of uveitis in vivo (Barry et al., 2007).

\section{Tocotrienol: Evidences of antioxidant and anti-inflammatory effects}

Tocotrienol are capable of scavenging and reducing reactive oxygen species. The antioxidative activity resides mainly with its "chain-breaking" property, which neutralizes peroxyl and alkoxyl radicals generated during lipid peroxidation (Yoshida, et al., 2007). Tocotrienol on the other hand, found in abundance in palm oil used for frying and consider as a potent antioxidant. The main role of the antioxidants represent by mopping up reactive oxygen species (ROS) which is consider one of the potent activator of oxidative stress-induced inflammation (Kamat and Devasagayam, 1995). Tocotrienol is one of the active compounds found in palm oil, together with the more abundant tocopherol (Yoshida, et al., 2007).

Tocopherol has been widely researched and recently was found to control the levels of pro-inflammatory cytokines such as interleukin (IL)-6 by down regulating its expression (Noriko et al., 1999; Sharma and Vinayak, 2011). $\delta$-tocotrienol has been shown to block LPS-induced expression of TNF- $\alpha$, IL-1 $\beta$, IL-6 and iNOS in macrophages (Qureshi et al., 2010).The average level of vitamin E (alpha tocopherol) was lower in individuals with macular degeneration than in age and risk matched controls (Satici et al., 2003; Williams, 2006). In placebo-controlled studies, oral vitamin $\mathrm{E}$ was able to increase the glutathione levels in the aqueous humor and lenses of humans, rabbits and rats (Bilgihan et al., 2003). Oxidative processes have been implicated in the causation of both cataracts and the age-related disorder of the retina, maculopathy. Cataracts occur when the transparent material in the lens of the eye becomes cloudy and opaque. Oxidation, induced mainly by 
exposure to ultraviolet light, is believed to be a major cause of damage to the proteins of the lens. Garrett et al., (1999) reported that the average level ofvitamin E (alpha tocopherol) was lower in individualswith macular degeneration than in age and risk matchedcontrols in placebo-controlled studies, oral vitamin Ewas able to increase the glutathione levels in the aqueoushumor and lenses of humans, rabbits and rats.Supplementation of 400IU vitamin $\mathrm{E}$ (as natural $\mathrm{D}$-alphatocopherol) is commonly recommended to all individuals to help with the 'normal' oxidative load (Seddon et al., 2005). All three of the major dietary antioxidants (vitamin $\mathrm{C}$, vitamin $\mathrm{E}$ and carotenoids) have been associated with decreased cataract risk through the retardation of lens opacity(Leeuwen et al., 2005).Therefore the low plasma levels of vitamin $\mathrm{E}$ were associated with the worsening of early cortical lens opacities (Chiu and Taylor, 2007; Sanz et al., 2007)

Taylor et al., (2002) investigated the effects of thecombined antioxidant vitamins $\mathrm{A}, \mathrm{C}$, and $\mathrm{E}$ and zinc onthe development of cataract and (age-related macular degeneration) AMD and showed some partial protective effect of antioxidantsupplements on the progression of moderatelyadvanced AMD (Washington et al., 2001). Age-related eye disease study group(AREDS) (2001), used a randomized,placebo-controlled clinical trial, comprising3640 participants, using supplementationwith high-dose antioxidants(average follow-up 6.5 years) showeda significant reduction in rates of atleast moderate visual loss in certaincategories of ARM. Participants wererandomized to daily antioxidants(vitamin C $500 \mathrm{mg}$, vitamin E $400 \mathrm{IU}, \mathrm{b}$-carotene $15 \mathrm{mg}$, zinc $80 \mathrm{mg}$ andcopper $2 \mathrm{mg}$ ) or placebo. Subjectswith extensive intermediate size drusen, at least one large druse, non-centralgeographic atrophy in one or botheyes, or advanced ARM in one eyehad statistically significant odds reduction for the development ofadvanced (late) ARM. At 5 years, theestimated probability of progression toadvanced ARM (neovascular ARM,geographic atrophy) was $28 \%$ forthose assigned to placebo, and $20 \%$ for those assigned to antioxidants pluszinc.

Vague effects of the natural antioxidant vitamin $\mathrm{E}$ have been described in its relation to sugar cataract development in rodents: a significant prevention of cataractogenesisand an improvement of lens biochemical indices, without affecting the visual cataract score (Ohta et al., 2000). A randomized controlled trial of vitamin E supplementation has not shownany effect on the incidence of early AMD after 4 years of follow-up (Flood et al. 2002). In contrast with the aforementioned studies, our results were based on long-term follow-up of a large, population- based cohort with thorough baseline assessment of dietary intake.Recently, a meta-analysis of 19 clinical trials including AREDS showed that high-dosage (400 IU/d) vitamin E supplementation may increase in all-cause mortality (Miller et al., 2005).Tocotrienols also displayed potent anti-inflammatory activity by inhibiting IL-6 and TNF- $\alpha$ These are the major proinflammatory cytokines released by activated macrophages. IL-6 has been massively studied due to its correlation with poor prognosis and resistance to therapy, interestingly; $\delta$-tocotrienol demonstrated a $51 \%$ reduction in IL-6 levels in LPS-stimulated macrophages (Mun et al., 2009; Ndlovu et al., 2009).

\section{Curcumin: Evidences of anti-inflammatory effects}

Curcumin, a yellow coloured phenolic pigment extracted from the rhizome of herb Curcuma longa, is widely reported to have potent anti-oxidative, anti-inflammatory and anticarcinogenic effects. The anti-inflammatory action of curcumin seems to be closely related to inhibition of TNF- $\alpha$ and other inflammatory cytokines production and suppression of $\mathrm{NF}-\kappa \mathrm{B}$ activation by blocking phosphorylation of inhibitory factor I-kappa B kinase (IкB) (Kim et al., 2003). Curcumin is widely used for our preparation of food. Curcumin can be found in turmeric, which is the powdered form of Curcuma longa rhizomes, Curcumin has been shown to have anti-inflammatory activity when applied topically in EIU (Gupta et al., 2008). Curcumin exerts its antiinflammatory effects by up regulating the expression of PPAR $\gamma$ (Siddiqui et al., 2006) and by direct action on PPAR $\gamma$ receptor (Rinwa et al., 2011) thus leading to inhibition of the NF-kB pathway (Zhong et al., 2011). Curcumin was also noted to increase neutrophil apoptosis (Siddiqui et al., 2006). Although topical preparation of curcumin has been shown to reduce the level of tumour necrosis factor- $\alpha$ (TNF- $\alpha$, one of several pro-inflammatory cytokines) (Gupta et al., 2008), the direct effect of curcumin on the expression of pro-inflammatory cytokines has not been demonstrated. Ukil et al (2003) investigated the protective effects of curcumin on 2, 4, 6-trinitrobenzenesulphonic acid (TNBS)induced colitis in mice which is a model of Inflammatory bowel disease (IBD). It also had been shown in curcumin-pretreated mice; there was a significant reduction in the degree of both neutrophil infiltration and lipid peroxidation in the inflamed colon as well as decreased serine protease activity (Bereswill et al., 2010; Lin et al., 2011). Curcumin also reduced the levels of $\mathrm{NO}$ and $\mathrm{O}^{-}$associated with the favorable expression of Th1 and Th2 cytokines and inducible NOS. Consistent with these observations, NF- $\kappa B$ activation in colonic mucosa was suppressed in the curcumin treated mice; therefore the studies suggested that curcumin can exert beneficial effects in experimental colitis (Aggarwal et al., 2003; Kunsch et al., 2004; Sikora et al., 2010). The curcumin also have been shown an inhibitory effect on protein kinase $\mathrm{C}$ and xanthine oxidase (Kuo et al., 1996; Chao et al., 2007).

Pan et al., (2000) demonstrated that the nuclear factor kappa B (NF- $\kappa$ B2) which consider the master factor playing a role in the inflammatory and immune response, was suppressed by curcumin through inhibiting the activity of I- $\kappa \mathrm{B}$ kinase (IKK). In principle, curcumin has been widely demonstrated to have potent antioxidant activities. It is well known that reactive oxygen species (ROS) play a key role in enhancing inflammation through the activation of stress kinases and redox sensitive transcription factors

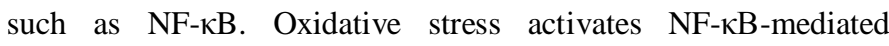
transcription of pro-inflammatory mediators either through the activation of its activating inhibitor IKK or the enhanced recruitment or activation of transcriptional co-activators (Samuhasaneeto et al., 2009; Naik et al., 2011). 
Although numerous different pathways are activated during the inflammatory response, NF- $\kappa \mathrm{B}$ is thought to be of the most importance in cancer-related inflammation (Philip and Rowley, 2004). However, curcumin acts as ROS scavenger, increases antioxidant glutathione levels by induction of glutamate cysteine ligase and acts as an anti-inflammatory agent by inhibition of NF- $\kappa \mathrm{B}$ signaling (Biswas et al., 2005). Persistent activation of $\mathrm{NF}-\kappa \mathrm{B}$ has been observed in many different cancers research. Interestingly, Lu et al., (2004) have been identified that the sustained kinase (IKK) activation is achieved to activate NF- $\mathrm{BB}$ pathway in many types of human cancer, indicating the activation of $\mathrm{NF}-\kappa \mathrm{B}$ is likely to result from alterations in its upstream signaling components. In addition, cytotoxic studies in different cell lines have indicated that the toxicity of curcumin was significantly higher in tumor cells if compared to the normal cells (Kunwar et al., 2008).

Basically, curcumin prevents tissue damage by at least two mechanisms: acting as an antioxidant and by inhibiting NF- $\mathrm{KB}$ activation to minimized oxidative stress (Shapiro et al., 2006; Reyes-Gordillo et al., 2007). Interestingly, feeding curcumin to the diabetic rats controls oxidative stress by inhibiting the increase in thiobarbituric acid reactive substances (TBARS) and protein carbonyls by reversing altered antioxidant enzyme activities without altering the hyperglycemic state (Suryanarayana et al., 2007). By inhibiting ROS generation, curcumin also protects pancreatic islets against $\beta$ cell toxins (Kanitkar and Bhonde, 2008).

All evidence shows that curcumin appears to be beneficial in preventing diabetes-induced oxidative stress, and the inhibition of NF- $\mathrm{BB}$-dependent pathway is at least in part involved in the anti-diabetic mechanisms. Curcumin has long been expected to be a therapeutic or preventive agent for several major human diseases because of its anti-oxidative, anti-inflammatory, and anti-cancerous effects. As well as the absorption, bioavailability and metabolism of curcumin have been studied in humans (Chen et al., 2010). In 2001 research have been demonstrated that curcumin is not toxic to humans up to $8,000 \mathrm{mg} /$ day when taken for 3 months (Cheng et al., 2001; Fu et al., 2008). In considering all of these discoveries, therefore, curcumin can be considered as an ideal lead compound for anti-inflammatory and anticancer drug development.In one small study, curcumin was given orally to 32 chronic anterior uveitis patients who were divided into two groups. The first group received curcumin alone, whereas the second group received a combination of curcumin and antitubercular treatment, all the patients treated with curcumin alone improved, compared to a response rate of $86 \%$ among those receiving the combination therapy (Lal et al., 1999).

Similar research conducted on rats and rabbits found that curcumin effectively inhibited chemically induced cataract formation, even at very low dietary levels (Pandya et al., 2000).Awasthi et al., (1996) found the as a potential cataract therapy, researchers fed two groups of rats diets that included corn oil, or a combination of curcumin and corn oil for 14 days. Afterward, their lenses were removed and examined for the presence of lipid peroxidation. The scientists discovered that "the lenses from curcumin-treated rats were much more resistant to inducedopacification than were lenses from control animals (Chen et al., 2010).Curcuminhave also found exhibited anti-inflammatory effects instandard animal models used for testing antiinflammatory activity as well inhibit leukotriene formation in rat peritonealpolymorphonuclear neutrophils (Lal et al., 1999; Reyes et al., 2007). Possible benefits of oralcurcumin supplementation have been observed in cases ofchronic anterior uveitis as in the case of berberine, curcuminexhibits an ability to suppress TNF- $\alpha$ activity and cytokineproduction in experimental acute liver injury (Chen et al., 2010).

Gupta et al., (2008) demonstrated a significantantiinflammatory effect including improvementof chronic uveitis by oral supplementation. The reduced severity of inflammatorychanges observed in histopathologic examinationand clinical manifestations in the inflamed eye was the result ofsignificant inhibition of vascular and cellular inflammatory responses. The release of chemical mediators of inflammation isalso suppressed secondary to inhibition of the cellular response. The suppression of vascular and cellular inflammatoryresponses by herbal extracts was evidenced by significantlylow levels of inflammatory cells, proteins, and TNF-alevel inaqueous humor of treated animals. Significantly reduced protein levels in aqueous humor also indicate a possible inhibitoryrole of extract constituents on leukocyte adherence to thevascular endothelium (Allegri et al., 2010).

Kumar et al., (2005) reported that curcumin feeding to rats with chemical-induced hyperglycemia can reduce oxidative stress that is the main cause of progression of cataract (Bengmark, 2006). The beneficial effects of this drug appear now to be related to the effect on up regulation of peroxisome proliferator-activated receptor- $\gamma$ (PPAR- $\gamma$ ), which is a ligandinducible transcription factor involved mainly in controlling inflammation in peripheral organs. Activation of PPAR- $\gamma$ has been shown to control the response in microglial cells and limit inflammation (Brigh, 2007; Jacob et al., 2007; Nonn et al., 2007). Curcumin also has been shown significant effect to prevent choroidal and retinal neovascularization in several experimental animal models, notably through the inhibition of VEGF receptor expression (Jacob et al., 2007; Shakibaei et al., 2007; Allegri et al., 2010).

\section{CONCLUSION}

Vitamin E, especially the Tocotrienol and regulation of disease has been extensivelystudied in humans, animal models and cell systems. Most ofthese studies focus on the tocopherol isoform of vitamin E.These reports indicate contradictory outcomes for anti-inflammatory functions of the tocopherol isoform of vitaminE. These seemingly disparate clinical resultsare consistent with recently reported unrecognizedproperties of isoforms of vitamin E. The anti-inflammatorypotential of tocotrienols lookspromising and further studiesshould be spear-headed. Understanding of the properties oftocotrienols would lead to greater benefits andprovide good options when planning for thehealth of the public. Tocotrienol treatment has several anti-inflammatory effects that could be mechanistically analogous to the modulation of proteasomal 
activity by lactacystin, a well-established proteasome inhibitor that can either increase or decrease proteasomal activity under different conditionsand finally will lead to give good prognosis for chronic disease (Qureshi et al., 2010).In other hand the supplementation ofcurcumin has been shown to be safein humans. The mechanism by which curcumin induces itsanti-inflammatory effects is yet to be fully elucidated, butmany studies have shown its relevance as a potent anti-inflammatory and immuno-modulating agent. PPAR- $\gamma$ agonists(like curcumin) act on microglia and immune systemcells modulating both innate and adaptive immune responses, and can have a profound effect on the inflammatory cascade. The positive results of the previous study show that Norflo (curcuminphosphatidylcholinecomplex) can play an important rolein the adjunctive therapy of chronic diseasein various origins and gives a contribution to the clinical potential efficacy of thisplant-derived product in medicine (Allegri et al., 2010).

\section{REFERENCES}

Awasthi $\mathrm{S}$ et al. Curcumin protects against 4-hydroxy-2-transnonenal-induced cataract formation in rat lenses. Am J ClinNutr 1996; 64(5):761-6

Bengmark S. Curcumin an atoxic antioxidant and natural NFkappab, cycclooxygenase-2, lipooxygenase and inducible nitric oxide synthase inhibitor: a shield against acute and chronic diseases. J Par EntNutr. 2006;30(1):61-62.

Bilgihan, K. Bilgihan, O. Yis, C. Sezer, G. Akyol, and B. Hasanreisoglu, "Effects of topical vitamin E on corneal superoxide dismutase, glutathione peroxidase activities andpolymorphonuclear leucocyte infiltration after photorefractive keratectomy," ActaOphthalmologicaScandinavica, 2003;81(2): 177-180.

Bharat B. Aggarwal, Anushree Kumar and Alok C. Bharti. Anticancer Potential of Curcumin: Preclinical and Clinical Studies. Anticancer Research 2003;23: 363-398.

Bright JJ. Curcumin and autoimmune disease. AdvExp Med Biol. 2007;595:425-451.

Balci M, Devrim E, Durak I. Effects of mobile phones on oxidant/antioxidant balance in cornea and lens of rats. Curr Eye Res. 2007; 32:21-5.

Biswas SK, McClure D, Jimenez LA, Megson IL, Rahman I. Curcumin induces glutathione biosynthesis and inhibits NF-Bactivation and interleukin-8 release in alveolar epithelial cells: mechanism of free radical scavenging activity. Antioxid Redox Signal. 2005; 7: 32-41.

Barry S. Winkler, Michael E. Boulton, John D. Gottsch, and Paul Sternberg.Oxidative damage and age-related macular degeneration.Mol Vis. Author manuscript; available in PMC 2007 January 17

Bacsi A, Dharajiya N, Choudhury BK, et al. Effect of pollenmediated oxidative stress on immediate hypersensitivity reactions and latephase inflammation in allergic conjunctivitis. J Allergy ClinImmunol 2005; 116:836-43

Biswas SK, McClure D, Jimenez LA, Megson IL, Rahman I. Curcumin induces glutathione biosynthesis and inhibits NF-Bactivation and interleukin-8 release in alveolar epithelial cells: mechanism of free radical scavenging activity. Antioxid Redox Signal 7: 32-41, 2005.

Chung HS, Harris A, Kagemann L, et al. Vascular aspects in the pathophysiology of glaucomatous optic neuropathy. SurvOphthalmol 1999; 43(Suppl 1):S43-50.

Chao JW, Lee KS, Kim CW. Curcumin attenuates the expression of IL-1, IL-6, and TNF-as well as cyclin E in TNF--treated HaCaT cells; NF-B and MAPKs as potential upstream targets. Int J Mol Med 19: 469-474, 2007

Chiu CJ, Taylor A. 2007. Nutritional antioxidants and agerelated cataract and maculopathy.Exp Eye Res 84(2):229-245
Chiu CJ, Taylor A. Nutritional antioxidants and age-related cataract and maculopathy. Exp Eye Res 2007; 84: 229-245.

D C Gritz, M Srinivasan, S D Smith, U Kim, T M Lietman, J H Wilkins, B Priyadharshini, R K John, S Aravind, N V Prajna, R DuraisamiThulasiraj, J P Whitcher. The Antioxidants in Prevention of Cataracts Study: effects of antioxidant supplements on cataract progression in South India.Br J Ophthalmol2006; 90:847-851

Delcourt C, Lacroux A, CarriereI,Group. PS (2005) The ThreeYear Incidence of Age-Related Macular Degeneration: The "Pathologies OculairesLieesal'Age" (POLA) Prospective Study. Am J Ophthalmol, 140, 924-926.

Eye Disease Prevalence Research Group. Prevalence of agerelated macular degeneration in the United States.Arch Ophthalmol. 2004;122:564-572.

E Sikora, Giovanni Scapagniniand Mario Barbagall.Curcumin, inflammation, ageing and age-related diseases.Immun Ageing. 2010; 7: 1.

Flood V, Smith W, Wang JJ, Manzi F, Webb K, Mitchell P. Dietary antioxidant intake and incidence of early age-related maculopathy: the Blue Mountains Eye Study.Ophthalmology.2002; 109:2272- 2278.

$\mathrm{Fu}$ Y, Zheng S, Lin J, Ryerse J, Chen A. Curcumin protects the rat liver from CCl4-caused injury and fibrogenesis by attenuating oxidative stress and suppressing inflammation. MolPharmacol.2008;73:399-40

Ferreira SM, Lerner SF, Brunzini R, Evelson PA, Llesuy SF. Oxidative stress markers in aqueous humor of glaucoma patients. Am $J$ Ophthalmol2004; 137: 62-9

GoranBjelakovic, DimitrinkaNikolova;LiseLotteGluud; Rosa G. Simonetti; Christian Gluud, Mortality In Randomized Trials Of Antioxidant Supplements For Primary And Secondary Prevention. JAMA.January 11, 2012, Vol 307, No. 2, Pp 115-213

Gery I, Nussenblatt RB, Chan CC and Caspi RR: Autoimmune diseases of the eye. In: The Molecular Pathology of Autoimmune Diseases. Theofilopoulos AN and Bona CA (eds). 2nd edition, Taylor and Francis, New York, pp1575-1609, 2002.

Garret DA, Failla M.L., Sarama R.J., Development of an in vitro digestion method to access carotenoid bioavailability from meals. J. Agric. Food Chem., 1999, 47, 4301-4309.

Gupta, S.K., et freeze al., The anti-inflammatory effects of Curcuma longa and Berberis aristatafreeze in endotoxin-induced uveitis in rabbits. Invest Ophthalmol Vis Sci, 2008. 49(9): p. 4036-40.

Imamura Y, Noda S, Hashizume K, Shinoda K, Yamaguchi M, Uchiyama $\mathrm{S}$, et al. Drusen, choroidal neovascularization, and retinal pigment epithelium dysfunction in SOD1-deficient mice: a model of agerelated macular degeneration. ProcNatlAcadSci U S A. 2006; 103(30):11282-7.

Hugh R Taylor, Gabriella Tikellis, Luba D Robman, Catherine A McCarty, John J McNeil. Vitamin E supplementation and macular degeneration: randomised controlled trial. BMJ, volume 3256 July 2002.

Jennifer S.L. Tan,Jie Jin Wang, Victoria Flood, Wayne Smith, Paul Mitchell. Dietary Antioxidants and the Long-term Incidence of AgeRelated Macular Degeneration: The Blue Mountains Eye Study. Am J ClinNutr2008; 87:1899-1905.

Jui-An Lin; Jenn-Han Chen, Yuan-Wen Lee, Chao-Shun Lin, Ming-Hui Hsieh,Chuen-Chau Chang,Chih-ShungWong, Judy Ju-Yi Chen, Geng-Chang Yeh,Feng-Yen Lin, and Ta-Liang Chen. Biphasic Effect of Curcumin onMorphine Tolerance:Preliminary Evidence from Cytokine/Chemokine Protein Array Analysis. Evidence-Based Complementary and Alternative Medicine, Volume 2011, Article ID 452153, 11 pages

Jacob A, Rongqian W, Zhou M, Wang P. Mechanism of the anti-inflammatory effect of curcumin: PPAR-activation. PPAR Res. 2007:89369.

Kumar PA, Suryanarayana P, Reddy PY, Reddy GB. Modulation of crystallin chaperone activity in diabetic rat lens by curcumin. Mol Vision. 2005;11:561-568.

Koh SW, Waschek JA. Corneal endothelial cell survival in organ cultures under acute oxidative stress: effect of VIP. Invest Ophthalmol Vis Sci 2000; 41:4085-92. 
Kamat JP, Devasagayam TP. Tocotrienol from palm oil as inhibitors of lipid peroxidation and protein oxidation in rat brain mitochondria.Neurosci.Lett. 1995; 195: 179-182.

Kruzel ML, Bacsi A, Choudhury BK, et al. Lactoferrin decreases pollen antigen-induced allergic airway inflammation in a murine model of asthma. Immunology. 2006; 119:159-66.

Kim HY, Park EJ, Joe EH, Jou I. Curcumin suppresses Janus kinase-STAT inflammatory signaling through activation of Src homology 2 domain-containing tyrosine phosphatase 2 in brain microglia. $\mathbf{J}$ Immunol. 2003;171:6072-9

Kunsch C, Lunchoomun J, Grey JY, et al. Selective inhibition of endothelial and moncyte redox-sensitive genes by AG1-1067: a novel antioxidant and anti-inflammatory agent. J Pharm Exp.2004; 308:820-9.

Kuo ML, Huang TS, Lin JK. Curcumin, an antioxidant and antitumor promoter, induces apoptosis in human leukemia cells. BiochimBiophysActa 1317: 95-100, 1996.

Kunwar A, Barik A, Mishra B, Rathinasamy K, Pandey R, Priyadarsini KI. Quantitative cellular uptake, localization and cytotoxicity of curcumin in normal and tumor cells.BiochimBiophysActa 1780: 673679, 2008.

Liang FQ \& Godley BF (2003): Oxidative stress-induced mitochondrial DNA damage in human retinal pigment epithelial cells: a possible mechanism for RPE ageing and age-related macular degeneration. Exp Eye Res 76: 397-403.

Lal B et al. Efficacy of curcumin in the management of chronic anterior uveitis. Phytother Res 1999 Jun;13(4):318-22.

PiaAllegri; Antonio Mastromarino; PiergiorgioNeri. Management of chronic anterior uveitis relapses: efficacy of oral phospholipidiccurcumin treatment. Long-term follow-up. Clinical Ophthalmology 2010;4:1201-1206.

Miller ER III, Pastor-Barriuso R, Dalal D, Riemersma RA, Appel LJ, Guallar E. Meta-analysis: highdosage vitamin E supplementation may increase all-cause mortality. Ann Intern Med. 2005; 142: 37-46.

Mittag T. Role of oxygen radicals in ocular inflammation and cellular damage.Exp Eye Res.1984; 39:759-69.

Mohammad N. Qureshi, Bhanudansh S. Kuchekar2, Nadeem A. Logadeand Majid A. Haleem. In-vitro Antioxidant and In-vivo Hepatoprotective activity of Leucasciliataleaves. Rec. Nat. Prod. 4:2 (2010) 124-130

M.M Sanz; L.E Johnson; S. Ahuja; P.A. Ekstrom.J.Romero. T Van veen.Significant photoreceptor rescue by treatment with a combination of antioxidants in an animal model for retinal degeneration. Neuroscience, 2007; 145(3), 1120-1129.

M Kanitkar, K Gokhale, S Galande, R RBhonde.Novel role of curcumin in the prevention of cytokine-induced islet death in vitro and diabetogenesisin vivo. British J Pharmacol. 2008; 155, 702-713

Min Chen, Dan-Ning Hu, Zan Pan, Cheng-Wei Lu, Chun-Yan Xue, IvarAass .Curcumin protects against hyperosmoticity-induced IL1beta elevation in human corneal epithelial cell via MAPK pathways. Exp Eye Res. 2010; 90(3):437-43

Mun-Li, Y., S.R. Abdul Hafid, C. Hwee-Ming, \& K. Nesaretnam. Toocotrienols suppress proinflammatorymarkers and cyclooxygenase-2 expression in RAW264.7macrophages. Lipids 2009; 44:787-797.

Ndlovu, M.N., C.V. Lint, K.V. Wesemael, et al.. HyperactivatedNF-kB and AP-1 transcription factors promotehighly accessible chromatin and constitutive transcriptionacross the Interleukin-6 gene promoter in metastatic breastcancer cells. Mol. Cell. Biol. 2009; 29(20): 5488-5504.

N Washington St, Suite,Rockville, MD. A Randomized, Placebo-Controlled, Clinical Trial of High-Dose Supplementation with Vitamins $\mathrm{C}$ and $\mathrm{E}$ and Beta Carotene for Age-Related Cataract and Vision Loss. Arch Ophthalmol.2001; 119 (10): 1439-1452

Nonn L, Duong D, Preehl DM. Chemopreventive antiinflammatory activities of curcumin and other phytochemicals mediated by MAP kinase phosphatase-5 in prostate cells. Carcinogenesis. 2007;28: 1188-1196.

Noriko Miyamoto, Michiko Mandai, Izumi Suzuma, Kiyoshi Suzuma, Kaori Kobayashi and Yoshihito Honda.Estrogen Protects Against
Cellular Infiltration by Reducing the Expressions of E-Selectin and IL-6 in Endotoxin-Induced Uveitis ${ }^{1}$ J Immunol, 1999, 163: 374-379.

PiaAllegri; Antonio Mastromarino; Piergiorgio Neri. Management of chronic anterior uveitisrelapses: efficacy of oral phospholipidiccurcumin treatment. Long-term follow-up. Clinical Ophthalmology 2010:4 1201-1206

Ohta Y, Yamasaki T, Niwa T, Majima Y. Preventive effect of vitamin E-containing liposome instillation on cataract progression in 12 month-old rats fed a 25\% galactose diet. J OculPharmacolTher 2000; 16:323-35.

Pandya $\mathrm{U}$ et al. Dietary curcumin prevents ocular toxicity of naphthalene in rats. ToxicolLett 2000 Jun 5; 115(3):195-204.

Pan MH, Lin-Shiau SY, Lin JK. Comparative studies on the suppression of nitric oxide synthase by curcumin and its hydrogenated metabolites through down-regulation of B kinase and NF-B activation in macrophages.BiochemPharmacol 60: 1665-1676, 2000.

Philip M, Rowley DA, Schreiber H. Inflammation as a tumor promoter in cancer induction. Semin Cancer Biol 14: 433-439, 2004

Reyes-Gordillo K, Segovia J, Shibayama M, Vergara P, Moreno MG, Muriel P. Curcumin protects against acute liver damage in the rat by inhibiting NF-kappaB, proinflammatory cytokines production and oxidative stress. BiochimBiophysActa. 2007;1770(6):989-996.

Renu Sharma and Manjula Vinayak. $\alpha$-Tocopherol attenuates NF- $\kappa \mathrm{B}$ activation and pro-inflammatory cytokine IL-6 secretion in cancerbearing mice.Bioscience Reports (2011) 31, (421-428

Rinwa P, Kaur B, Jaggi AS, Singh N. Involvement of PPARgamma in curcumin-mediated beneficial effects in experimental dementia. NaunynSchmiedebergs Arch Pharmacol.2010; 381:529-39.

Reyes-Gordillo K, Segovia J, Shibayama M, Vergara P, Moreno MG, Muriel P. Curcumin protects against acute liver damage in the rat by inhibiting NF- $\mathrm{KB}$, proinflammatory cytokines production and oxidative stress. BiochimBiophysActa 1770: 989-996, 2007.

Shakibaei M, John T, Schulze-Tanzil G, Lehmann I, Mobasheri A. Suppression of NF-kappaB activation by curcumin leads to inhibitionof expression of cyclo-oxygenase-2 and matrix-metalloproteinase-9 in human articular chondrocytes: implications for the treatment of osteoarthritis. BiochemPharmacol. 2007;73:1434-1445.

Sies, H., 1997. Oxidative stress: Oxidants and antioxidants. Exp. Physiol., 82: 291-295.

Saraswathy S, Rao NA. Photoreceptor mitochondrial oxidative stress in experimental autoimmune uveitis. Ophthalmic Res. 2009; 40:160164.

Samuhasaneeto S, Thong-Ngam D, Kulaputana O, Suyasunanont D, Klaikeaw N. Curcumin decreased oxidative stress, inhibited NF-kappaB activation, and improved liver pathology in ethanolinduced liver injury in rats. J Biomed Biotechnol.2009;2009:981963

Stefan Bereswill, Melba Munoz, Andre Fischer, Rita Plickert, Lea-Maxie Haag, Bettina Otto, AnjaA.Ku hl2, ChristophLoddenkemper, Ulf B. Gobel, Markus M. Heimesaat Anti-Inflammatory Effects of Resveratrol, Curcumin andSimvastatin in Acute Small Intestinal Inflammation. PLoS ONE 5(12). 2010

S.K.M. Garrett, J.J. McNeil, C. Silagy, M. Sinclair, A.P. Thomas, L.P. Robman, C.A. McCarty, G. Tikellis and H.R. Taylor R. Methodology of the VECAT study: Vitamin E intervention in cataract and age-related maculopathy. Ophthalmic Epidemiology. 1999, Vol. 6, No. 3 , Pages 195-208.

Sanz MM, Johnson LE, Ahuja S, Ekstrom PA, Romero J, van Veen T. Significant photoreceptor rescue by treatment with a combination of antioxidants in an animal model for retinal degeneration. Neuroscience 2007; 145: 1120-1129.

Seddon JM, George S, Rosner B \&Rifai M (2005): Progression of age-related macular degeneration. Prospective assessment of C-reactive protein, interleukin 6 and other cardiovascular biomarkers. Arch Ophthalmol 123: 774-782.

Seddon JM, Cote J, Rosner B. Progression of age-related macular degeneration: association with dietary fat, transunsaturated fat, nuts, and fish intake. Arch Ophthalmol 2003;121(12):1728-37.

Seddon JM, Cote J, Rosner B. Progression of age-related macular degeneration: association with dietary fat, transunsaturated fat, nuts, and fish intake. Arch Ophthalmol 2005;121(12):1728-37. 
Shapiro H, Ashkenazi M, Weizman N, Shahmurov M, Aeed H, Bruck R. Curcumin ameliorates acute thioacetamide-induced hepatotoxicity. J GastroenterolHepatol 21: 358-366, 2006.

Suryanarayana P, Satyanarayana A, Balakrishna N, Kumar PU, Reddy GB. Effect of turmeric and curcumin on oxidative stress and antioxidant enzymes in streptozotocin-induced diabetic rat. Med SciMonit 13: BR286-BR292, 2007.

Siddiqui AM, Cui X, Wu R, Dong W, Zhou M, Hu M, et al. The anti-inflammatory effect of curcumin in an experimental model of sepsis is mediated by up-regulation of peroxisome proliferator-activated receptorgamma. Crit Care Med. 2006;34:1874-82

Satici, M. Guzey, B. Gurler, H. Vural, and T. Gurkan, "Malondialdehyde and antioxidant enzyme levels in the aqueous humor of rabbits in endotoxin-induced uveitis," European Journal of Ophthalmology, vol. 13, no. 9-10, pp. 779- 783, 2003.

Taylor HR, Tikellis G, Robman LD, McCarty CA, McNeill JJ. Vitamin $\mathrm{E}$ supplementation and macular degeneration: randomised controlled clinical trial. BMJ.2002; 325:11.

Tezel G, Li LY, Patil RV, et al. TNF-alpha and TNF-alpha receptor-1 in the retina of normal and glaucomatous eyes. Invest Ophthalmol Vis Sci 2001; 42:1787-94.

Tezel G. Oxidative stress in glaucomatous neurodegeneration: mechanisms and consequences. ProgRetin Eye Res 2006; 25(5):490-513.
Ukil A, Maity S, Karmakar S, Datta N, Vedasiromoni JR, Das PK. Curcumin, the major component of food flavour turmeric, reduces mucosal injury in trinitrobenzenesulphonic acid-induced colitis. $\mathrm{Br} \mathrm{J}$ Pharmacol. 2003 May;139(2):209-18.

Van Leeuwen R, Boekhoorn S, Vingerling JR, Witterman JC, Klaver CC, Hofman A, et al. Dietary intake of antioxidants and risk of age-related macular degeneration. JAMA 2005; 294: 3101-3107.

$\mathrm{Wu}$ GS, Lee TD, Moore RE, Rao NA.Photoreceptor mitochondrial tyrosine nitration in experimental uveitis.Invest Ophthalmol Vis Sci. 2005; 46:2271-2281.

Wakamatsu K, Hu D-H, McCormick A, Ito S (2008) Characterisation of melanin in human iridal and choridal melanocytes from eyes with various coloredirides. Pigment Cell Melanoma Res.

Williams DL, Munday P. The effect of a topical antioxidant formulation including $\mathrm{N}$-acetylcarnosine on canine cataract: a preliminary study. Vet Ophthalmol. 2006; 9(5):311-16.

Yoshida, Y.; Saito, Y.; Jones, L.S. and Shigeri, Y. (2007) Chemical reactivities and physical effects in comparison between tocopherols and tocotrienols: physiological significance and prospects as antioxidants. J. Biosci. Bioeng., 104, 439-445

Zhong F, Chen H, Han L, Jin Y, Wang W. "Curcumin attenuates lipopolysaccharide-induced renal inflammation."Biol Pharm Bull. 2011;34(2):226-32. 